\title{
Erratum of "Dystrophins, Utrophins, and Associated Scaffolding Complexes: Role in Mammalian Brain and Implications for Therapeutic Strategies"
}

\author{
Caroline Perronnet ${ }^{1,2}$ and Cyrille Vaillend ${ }^{1,2}$ \\ ${ }^{1}$ Univ Paris-Sud, Centre de Neurosciences Paris-Sud, UMR8195, Orsay, F-91405, France \\ ${ }^{2}$ CNRS, Orsay, F-91405, France \\ Correspondence should be addressed to Caroline Perronnet, caroline.perronnet@u-psud.fr \\ Received 5 July 2010; Accepted 14 July 2010 \\ Copyright (C) 2010 C. Perronnet and C. Vaillend. This is an open access article distributed under the Creative Commons \\ Attribution License, which permits unrestricted use, distribution, and reproduction in any medium, provided the original work is \\ properly cited.
}

Dystrophin structure is organized in four main domains. The $\mathrm{N}$-terminal domain (246 amino-acids) similar to $\alpha$-actinin contains several actin-binding sites and a calmodulinbinding site. The central rod domain (2840 aa) has 24 triplehelical spectrinlike repeats thought to give the protein a flexible structure, with several irregular short and long segments, and four proline-rich end regions. The cysteine-rich domain (280 aa) participates in the critical interaction of dystrophin with the transmembraneous DGC component, $\beta$-dystroglycan. The COOH-terminus (320 aa) is an $\alpha$-helical coiled coil region that binds to the cytosolic component dystrobrevin and may also modulate interactions with syntrophins and other DGC-associated proteins.

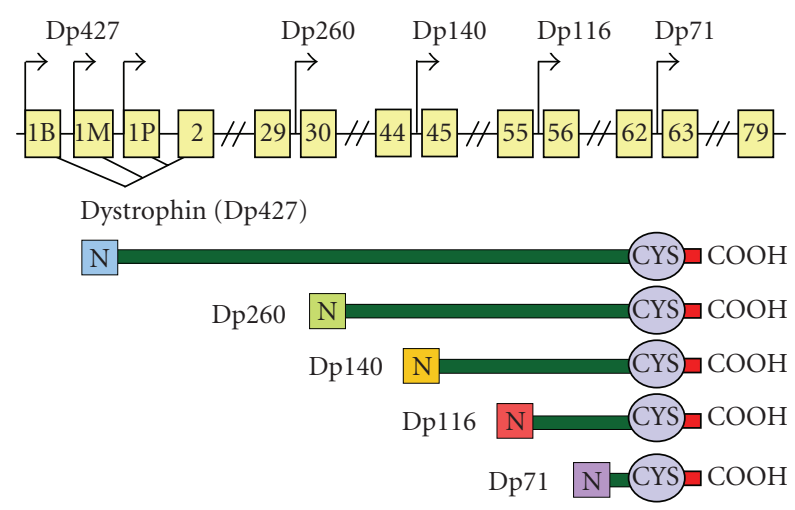

(a)

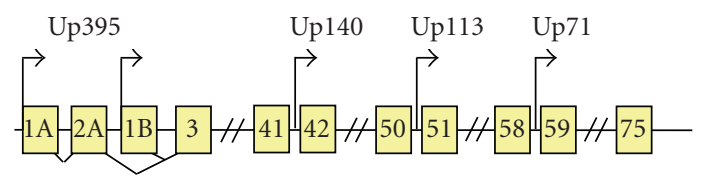

Utrophin (Up395)

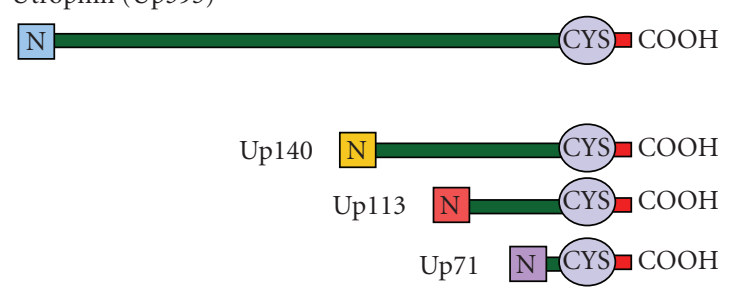

(b)

FiguRE 1 

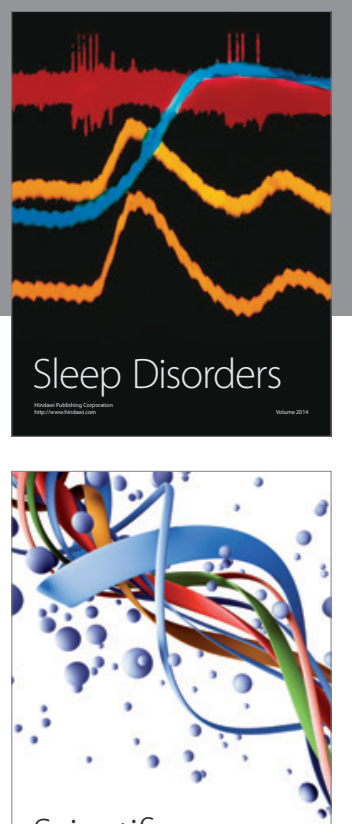

Scientifica
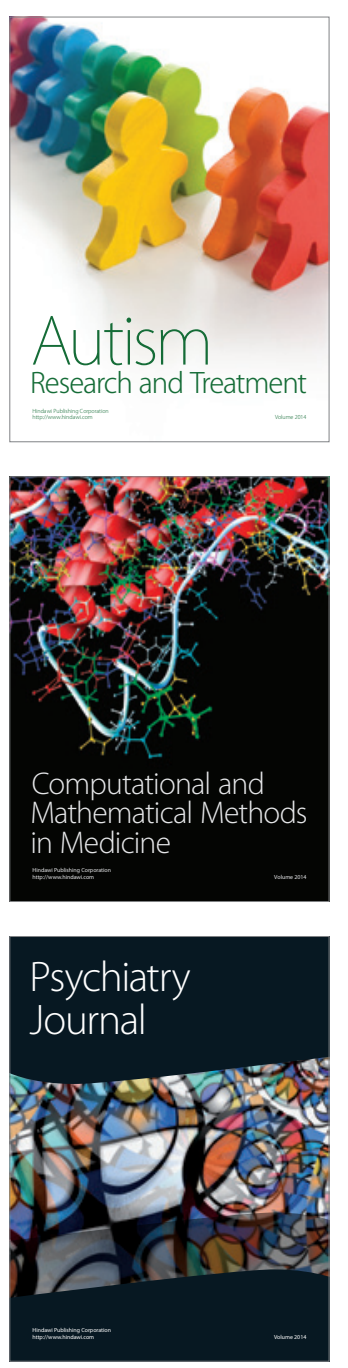
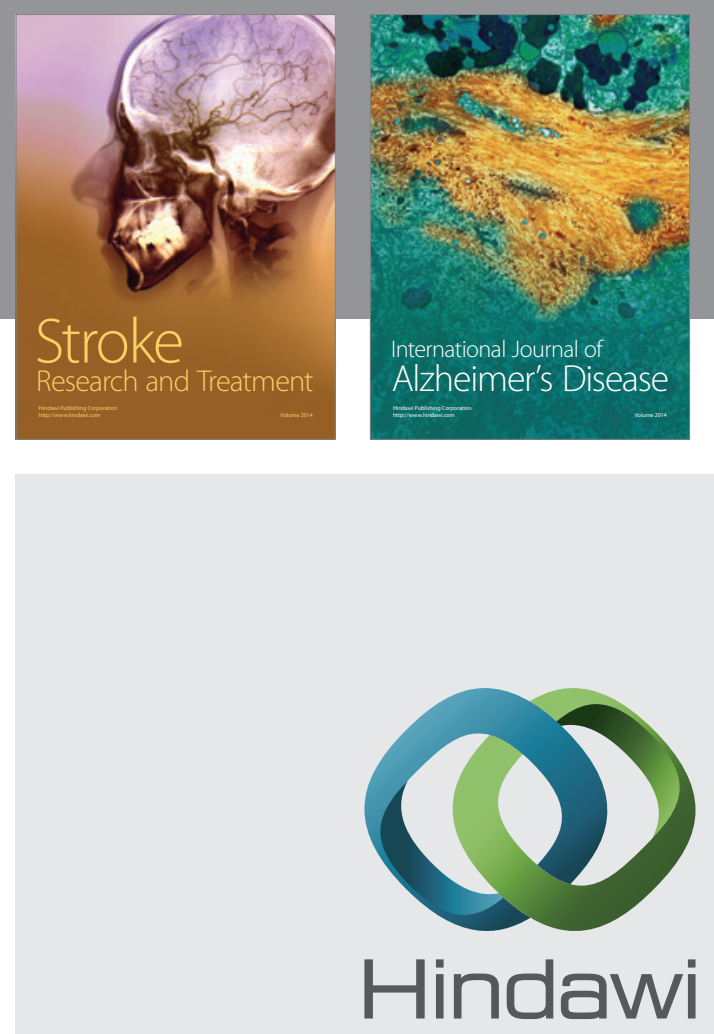

Submit your manuscripts at

http://www.hindawi.com
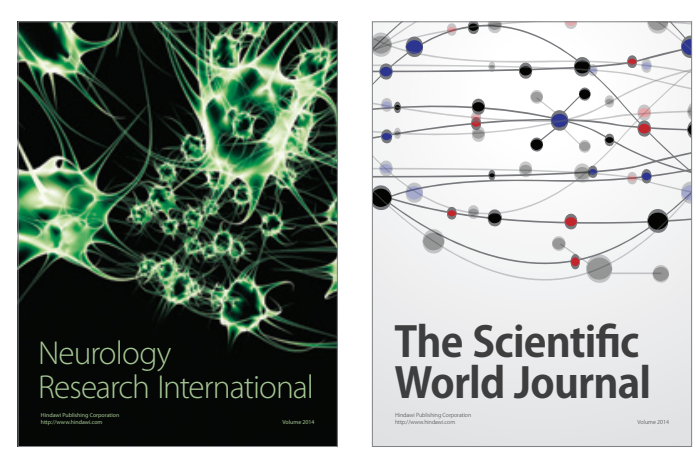

The Scientific World Journal

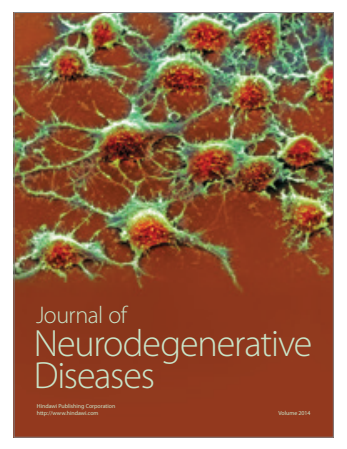

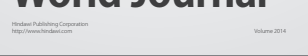

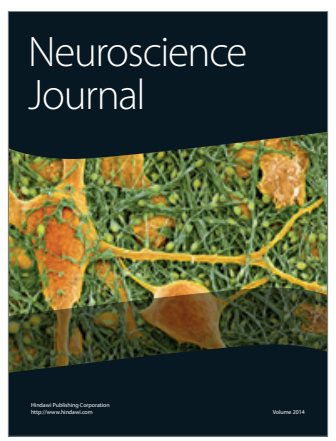

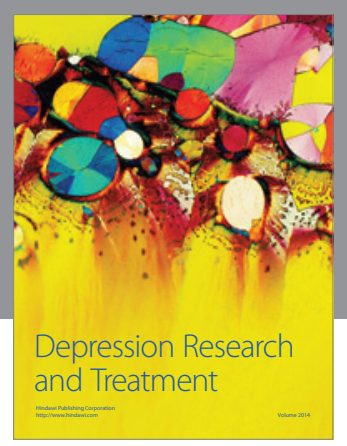
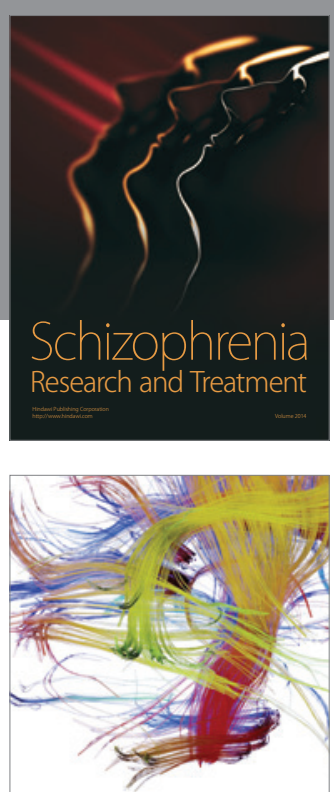

Brain Science

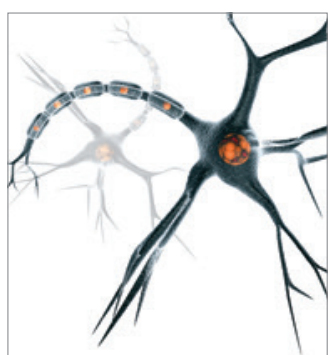

Neural Plasticity
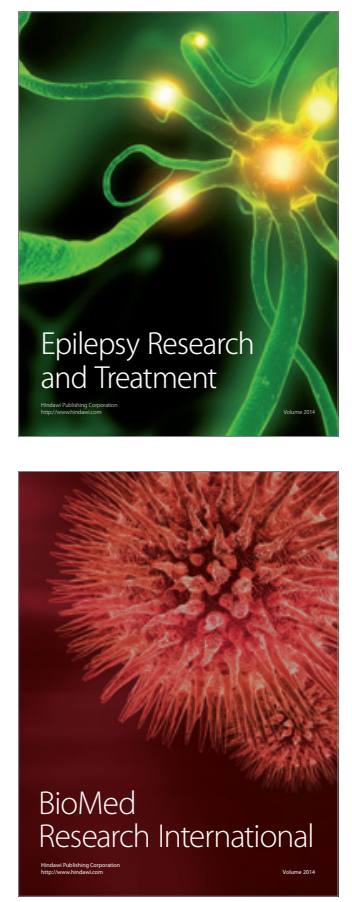

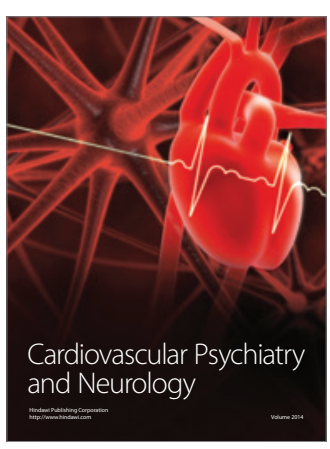

Parkinson's

Disease
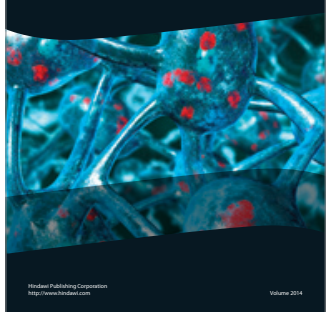